\title{
Effects of micronized progesterone added to non-oral estradiol on lipids and cardiovascular risk factors in early postmenopause: a clinical trial
}

\author{
Gislaine Casanova ${ }^{1,2+}$ and Poli Mara Spritzer ${ }^{1,2,3^{*}+}$
}

\begin{abstract}
Background: Much attention has been drawn to the deleterious effects of adding progestins to estrogen as hormone therapy (HT) in postmenopausal women. Some widely prescribed progestins have been shown to partially oppose the beneficial effects of estrogens on surrogate markers of cardiovascular disease (CVD) risk. Progestins with higher androgenic activity may interfere with lipid profile and glucose tolerance, and could affect mechanisms of estrogen-induced C-reactive protein (CRP) stimulation. Recent data have shown that norpregnane derivatives, but not micronized progesterone, increase the risk of venous thromboembolism among transdermal estrogens users. The aim of the present study was to assess the effects of combining micronized progesterone with non-oral estrogen therapy on lipid profile and cardiovascular risk factors in a sample of early postmenopausal women.

Methods: Clinical trial including 40 women receiving intranasal $17 \beta$ estradiol $3 \mathrm{mg} /$ day for two months and 46 women receiving percutaneous $17 \beta$ estradiol gel $1.5 \mathrm{mg} /$ day for three months (E2). Both groups received an additional $200 \mathrm{mg} /$ day of micronized progesterone by vaginal route 14 days/month (E2+P). Outcome measures included body weight, waist circumference, body mass index (BMI), lipid profile and ultra-sensitive C-reactive protein (usCRP) at baseline and during the E2 or E2+P portions of treatment.

Results: Mean age was $51 \pm 3$ years. Mean time since menopause was $22.2 \pm 10$ months. Most participants were overweight; HT did not change BMI. E2 and E2+P did not affect waist circumference and weight. Menopausal symptoms improved after HT. The effects of intranasal and percutaneous estradiol were similar, regardless of the addition of progesterone. Similarly, for the overall group of 86 women, micronized progesterone did not alter the response to E2. Blood pressure, glucose, insulin, $\mathrm{HDL}$-c, triglycerides, and usCRP remained constant with or without micronized progesterone. Total cholesterol decreased after E2, and progesterone maintained this reduction. LDL-C levels were similar at baseline and with E2, and lower during E2+P in relation to baseline.
\end{abstract}

Conclusions: Cyclic, short term exposure to vaginal micronized progesterone did not alter the metabolic and cardiovascular effects of non-oral E2 in early, apparently healthy, postmenopausal women.

Trial registration: ClinicalTrials.gov NCT01432028

Keywords: Lipid profile, Early postmenopause, Micronized progesterone, Non-oral estrogen, Hormone therapy

\footnotetext{
* Correspondence: spritzer@ufrgs.br

${ }^{\dagger}$ Equal contributors

'Gynecological Endocrinology Unit, Division of Endocrinology, Hospital de

Clínicas de Porto Alegre (HCPA), Rua Ramiro Barcelos, 2350, 90035-003 Porto

Alegre, Brazil

${ }^{2}$ National Institute of Hormones and Women's Health, CNPq, Rua Ramiro

Barcelos, 2350, 90035-003 Porto Alegre, Brazil

Full list of author information is available at the end of the article
} 


\section{Background}

Much attention has been drawn to the deleterious effects of adding progestins to estrogen as hormone therapy (HT) in postmenopausal women [1]. Recent prospective randomized studies have raised great concern regarding this combination, which has been linked to a negative impact on the cardiovascular and venous systems and on cognition [2], as well as to the development of breast cancer [3] in women in the menopause transition and postmenopause.

Progestogens encompass both progesterone, the physiological molecule synthesized and secreted by the ovary, and synthetic compounds named progestins [4]. All progestins share a progestogenic effect that causes the endometrium to enter the secretory phase and determines a decrease in endometrial disease [5]. However, other biological effects of progestins vary widely, since each progestin or progestin metabolite binds to specific steroid receptors. Some of the most widely prescribed progestins have been shown to partially oppose the beneficial effects of estrogens on surrogate markers of cardiovascular disease (CVD) risk [4]. Progestins with higher androgenic activity may interfere with lipid profile and glucose tolerance [6], and could affect mechanisms of estrogen-induced C-reactive protein (CRP) stimulation [7].

Even though the route of estrogen administration is known to be an important determinant of cardiovascular risk in postmenopausal women using HT [8], recent data have shown that norpregnane derivatives, but not micronized progesterone, increase the risk of venous thromboembolism among transdermal estrogens users [9]. A few studies indicate that micronized progesterone may have a better risk profile with respect to variables related to cardiovascular risk $[10,11]$. Therefore, not only the route of estrogen administration, but also the type of progestin may be important in determining the overall benefit-risk ratio for HT.

The aim of the present study was to assess the effects of combining natural micronized progesterone with non-oral estrogen therapy on variables related to lipid and hormonal profile and on ultra-sensitive C-reactive protein (usCRP) in a sample of early postmenopausal women.

\section{Results}

The mean age of participants was $51 \pm 3$ years, and 96\% were Caucasian (the remaining $4 \%$ were of mixed African and European ancestry). Mean age at menopause was $49.4 \pm 3$ years, and mean time since menopause was 22.2 \pm 10 months. Thirteen (15\%) patients were smokers.

The effects of intranasal and percutaneous gel were similar during E2 and E2+P (Table 1). Table 2 presents body mass index (BMI), weight, waist circumference, blood pressure and Kupperman score for menopausal symptoms before and during E2 and E2+P in the overall group of 86 participants. Most participants were overweight. BMI did not change with HT. Similarly, waist circumference, weight and systolic and diastolic blood pressure remained unchanged during HT with E2 alone or E2+P. At baseline, all patients presented menopausal symptoms that improved significantly with treatment, as shown by the Kupperman score (Table 2).

Table 3 shows metabolic variables and usCRP at baseline and during treatment for the overall group. Glucose, insulin, high-density lipoprotein cholesterol (HDL-c), triglycerides, and the high-sensitivity C-reactive protein test (hsCRP) remained constant after non-oral therapy with or without micronized progesterone. Total cholesterol decreased after E2-only treatment, and the addition of progesterone maintained this reduction. Low-density lipoprotein cholesterol (LDL-c) levels were similar at baseline and with E2 only, and were lower during E2+P treatment in relation to baseline.

\section{Discussion}

In the present study, cyclic exposure to vaginally administered micronized progesterone over the short term failed to affect lipid profile in early and apparently healthy postmenopausal women. Several studies have evaluated the relationship between estrogen dose and/or route of administration and cardiovascular benefit-risk ratio of HT in postmenopausal women. More recently, observational studies began to draw attention to the impact of using specific types of progestin in combination with estrogen. However, there is a paucity of data derived from clinical trials to assess the effect of different progestogens on variables related to cardiovascular risk. Therefore, this work provides an important contribution toward clarifying the impact of combined micronized progesterone plus non-oral estrogen therapy.

Menopause is a risk factor for CVD because of the ensuing endogenous estrogen deficiency, which has a detrimental effect on cardiovascular function and metabolism. Even though there are biologically plausible mechanisms of cardiovascular protection against harm produced by estrogen therapy, recent clinical trials suggest that estrogen may be associated with cardiovascular risk rather than benefit in the postmenopause [12]. However, reanalysis of these studies has indicated a possible protective window in which recent postmenopausal women in their sixth decade may benefit from HT $[1,13]$. In addition, it has been speculated that the cardioprotective benefits of HT may be more evident in the early postmenopausal period [14], although this is a controversial issue [15]. In the present study, the use of a sample of apparently healthy and relatively young (mean age of $51.3 \pm 3$ years) women who were postmenopausal for less than three years $(22.2 \pm 10$ months $)$ enabled us to more accurately demonstrate the neutral or beneficial 
Table 1 Anthropometric and clinical variables according to type of non-oral estradiol (intranasal or percutaneous gel)

\begin{tabular}{|c|c|c|c|c|c|c|c|}
\hline & \multicolumn{2}{|l|}{ Baseline } & \multicolumn{2}{|l|}{ E2 } & \multicolumn{2}{|l|}{$\mathrm{E} 2+\mathrm{P}$} & \multirow[t]{2}{*}{$P$} \\
\hline & $\begin{array}{l}\text { Intranasal } \\
n=40\end{array}$ & $\begin{array}{l}\text { Percutaneous } \\
n=46\end{array}$ & $\begin{array}{l}\text { Intranasal } \\
n=40\end{array}$ & $\begin{array}{l}\text { Percutaneous } \\
n=46\end{array}$ & $\begin{array}{l}\text { Intranasal } \\
n=40\end{array}$ & $\begin{array}{l}\text { Percutaneous } \\
n=46\end{array}$ & \\
\hline $\mathrm{BMI}$ & $26 \pm 3$ & $26 \pm 3$ & $26 \pm 3$ & $26 \pm 3$ & $26 \pm 3$ & $26 \pm 3$ & 0.6 \\
\hline Weight (kg) & $66 \pm 7$ & $64 \pm 9$ & $66 \pm 7$ & $64 \pm 9$ & $66 \pm 7$ & $64 \pm 10$ & 0.6 \\
\hline WC $(\mathrm{cm})$ & $84 \pm 6$ & $84 \pm 8$ & $84 \pm 6$ & $84 \pm 8$ & $83.5 \pm 5$ & $83.6 \pm 9$ & 0.6 \\
\hline $\mathrm{SBP}(\mathrm{mmHg})$ & $118 \pm 15$ & $119 \pm 12$ & $116 \pm 15$ & $114 \pm 15$ & $118 \pm 14$ & $116 \pm 14$ & 0.4 \\
\hline $\mathrm{DBP}(\mathrm{mmHg})$ & $75 \pm 7$ & $77 \pm 7$ & $75 \pm 9$ & $74 \pm 9$ & $76 \pm 10$ & $74 \pm 10$ & 0.2 \\
\hline Total-c (mg/dL) & $222 \pm 31^{\text {at }}$ & $211 \pm 27^{\text {at }}$ & $212 \pm 31^{\mathrm{bt}}$ & $201 \pm 27^{b+}$ & $205 \pm 31^{\text {bt }}$ & $200 \pm 32^{\mathrm{bt}}$ & 0.5 \\
\hline $\mathrm{HDL}-\mathrm{c}(\mathrm{mg} / \mathrm{dL})$ & $63 \pm 12$ & $63 \pm 18$ & $62 \pm 14$ & $60 \pm 15$ & $63 \pm 14$ & $60 \pm 16$ & 0.2 \\
\hline $\mathrm{LDL}-\mathrm{c}(\mathrm{mg} / \mathrm{dL})$ & $134 \pm 28^{\mathrm{a} \dagger}$ & $125 \pm 29^{\text {a† }}$ & $128 \pm 32^{\mathrm{a}, \mathrm{b} \dagger}$ & $118 \pm 26^{\mathrm{a}, \mathrm{b} t}$ & $121 \pm 26^{\mathrm{bt}}$ & $117 \pm 29^{\mathrm{bt}}$ & 0.5 \\
\hline Triglycerides (mg/dL) & $122 \pm 49$ & $117 \pm 56$ & $117 \pm 48$ & $114 \pm 54$ & $108 \pm 42$ & $115 \pm 62$ & 0.3 \\
\hline Fast glucose (mg/dL) & $91 \pm 11$ & $92 \pm 9$ & $91 \pm 8$ & $91 \pm 8$ & $93 \pm 11$ & $91 \pm 10$ & 0.2 \\
\hline $2 \mathrm{~h}$ glucose $(\mathrm{mg} / \mathrm{dL})$ & $106 \pm 29$ & $102 \pm 23$ & $113 \pm 38$ & $103 \pm 35$ & $110 \pm 39$ & $101 \pm 31$ & 0.2 \\
\hline Insulin $(\mu \mathrm{U} / \mathrm{mL})$ & $7(4-10)$ & $6(3-9)$ & $6(2-8)$ & $7(3-9)$ & $6(4-9)$ & $7(3-9)$ & 0.2 \\
\hline Estradiol $(\mathrm{pg} / \mathrm{mL})$ & $14(8-17)$ & $11(5-20)$ & $40(9-121)$ & $65(20-119)$ & $47(13-68)$ & 49 (10-96) & 0.1 \\
\hline hsCRP (mg/L) & $2.1(0.4-3.9)$ & $1.1(0.3-2.3)$ & $1.6(0.5-3)$ & $1.4(0.2-3)$ & $1.5(0.5-2)$ & $1(0.2-2)$ & 0.6 \\
\hline
\end{tabular}

Values expressed as median and interquartile range or mean \pm SD. Two-way analysis of variance with repeated measures (non parametric variables were log-converted for statistical analysis and reconverted for presentation in table format). $\mathrm{P}=$ difference between intranasal and percutaneous treatment.

$t=\mathrm{P}<0.01$ for difference between baseline, E2 and E2+P. Different superscript letters indicate statistical difference with Bonferroni multiple-comparison correction test $(a<5 \%)$.

Baseline: before hormone therapy; E2: estradiol only; E2+P estradiol + micronized progesterone.

Intranasal: $3 \mathrm{mg} /$ day $17 \beta$ estradiol by intranasal route $(n=40)$ for two months. Percutaneous: $1.5 \mathrm{mg} /$ day $17 \beta$ estradiol gel by percutaneous route $(n=53)$ for three months.

$B M I$ body mass index, $D B P$ diastolic blood pressure, $H D L$-c high-density lipoprotein cholesterol, $h s C R P$ high-sensitivity $C$-reactive protein test, $L D L-c$ low-density lipoprotein cholesterol, SBP systolic blood pressure, Total-c total lipoprotein cholesterol, $W C$ waist circumference, $2 \mathrm{~h}$ glucose: glucose levels $2 \mathrm{hours}$ after $75 \mathrm{~g}$ oral glucose load.

effects of HT with both non-oral E2 alone or in combination with micronized progesterone- combined period.

Blood pressure levels remained unchanged after HT in the present sample. Previous studies have shown that non-oral estrogen therapy associated with micronized progesterone had no deleterious effects on blood pressure in normotensive and controlled hypertensive postmenopausal women $[10,16]$. Estrogen increases the release of nitric oxide causing relaxation of smooth muscle cells and vasodilatation.
Progestins modulate the effects of estrogen on hepatic endocrine function through intrinsic androgenic properties. When co-administered with estrogen, progestogen may also have significant effects on body composition and metabolism because of its androgenic properties. The effects of HT on weight and body composition remain controversial [17]. In our study, non-oral E2 therapy with or without micronized progesterone did not modify waist circumference, BMI or body weight. Additionally, the treatment did not interfere with glucose or

Table 2 Clinical and anthropometric variables and menopausal symptoms $(n=86)$

\begin{tabular}{lllll}
\hline & Baseline & E2 & E2+P & P \\
\hline BMI & $26.3 \pm 3$ & $26.29 \pm 3$ & $26.23 \pm 3.1$ & 6.8 \\
\hline Weight $(\mathrm{kg})$ & $65.5 \pm 8.3$ & $65.58 \pm 8.3$ & 8.6 & 0.7 \\
\hline Waist circumference $(\mathrm{cm})$ & $84.3 \pm 7.5$ & $84.2 \pm 7.6$ & $83.5 \pm 7.4$ & $116.7 \pm 14.3$ \\
\hline Systolic blood pressure & $118.6 \pm 13.5$ & $115 \pm 14.9$ & $74.9 \pm 9.7$ & 0.06 \\
\hline Diastolic blood pressure & $76.2 \pm 7.3$ & $74.7 \pm 9.5$ & $4(0-8)^{\mathrm{b}}$ & 0.4 \\
\hline Kupperman score & $26(17-30)^{\mathrm{a}}$ & $6(0-12.5)^{\mathrm{b}}$ & $48(13-80)^{\mathrm{b}}$ & $<0.01$ \\
\hline E2 $(\mathrm{pg} / \mathrm{mL})$ & $13(5-19)^{\mathrm{a}}$ & $54(13-122)^{\mathrm{b}}$ & $<.01$ \\
\hline
\end{tabular}

Values expressed as median and interquartile range or mean \pm SD. $\mathrm{P}=$ two-way analysis of variance with repeated measures (non parametric variables were log-converted for statistical analysis and reconverted for presentation in table format).

Different superscript letters indicate statistical difference with Bonferroni multiple-comparison correction test $(a<5 \%)$.

Baseline: before hormone therapy; E2: estradiol only; E2+P estradiol + micronized progesterone.

$B M I$ body mass index. 
Table 3 Anthropometric and metabolic variables and markers of endothelial function $(n=86)$

\begin{tabular}{llllr}
\hline & Baseline & E2 & E2+P & \multicolumn{1}{l}{$\boldsymbol{P}$} \\
\hline Total-c $(\mathrm{mg} / \mathrm{dL})$ & $216 \pm 31^{\mathrm{a}}$ & $207 \pm 30^{\mathrm{b}}$ & $203 \pm 32^{\mathrm{b}}$ & $<0.01$ \\
\hline $\mathrm{HDL}-\mathrm{c}(\mathrm{mg} / \mathrm{dL})$ & $63 \pm 16$ & $61 \pm 15$ & $61 \pm 15$ & 0.06 \\
\hline LDL-c $(\mathrm{mg} / \mathrm{dL})$ & $129 \pm 29^{\mathrm{a}}$ & $123 \pm 29^{\mathrm{a}, \mathrm{b}}$ & $119 \pm 28^{\mathrm{b}}$ & $<0.01$ \\
\hline Triglycerides $(\mathrm{mg} / \mathrm{dL})$ & $120 \pm 53$ & $115 \pm 51$ & $111 \pm 53$ & 0.2 \\
\hline Fast glucose $(\mathrm{mg} / \mathrm{dL})$ & $91 \pm 11$ & $91 \pm 8$ & $92 \pm 11$ & 0.2 \\
\hline 2h glucose $(\mathrm{mg} / \mathrm{dL})$ & $103 \pm 27$ & $108 \pm 36$ & $105 \pm 36$ & 0.2 \\
\hline Insulin $(\mu \mathrm{U} / \mathrm{mL})$ & $6.9(3.9-9.7)$ & $6.2(2.8-8.8)$ & $6.9(3.8-9.1)$ & 0.2 \\
\hline hsCRP $(\mathrm{mg} / \mathrm{L})$ & $1.51(0.38-2.9)$ & $1.64(0.4-3)$ & $1.19(0.3-2.1)$ & 0.1 \\
\hline Val
\end{tabular}

Values expressed as median and interquartile range or mean \pm SD. $P=$ twoway analysis of variance with repeated measures (non parametric variables were log-converted for statistical analysis and reconverted for presentation in table format).

Different superscript letters indicate statistical difference with Bonferroni multiple-comparison correction test $(a<5 \%)$.

Baseline: before hormone therapy; E2: estradiol only; E2+P estradiol + micronized progesterone.

$H D L-c$ high-density lipoprotein cholesterol, hsCRP high-sensitivity C-reactive protein test, $L D L-c$ low-density lipoprotein cholesterol, Total-c total lipoprotein cholesterol; $2 \mathrm{~h}$ glucose: glucose levels 2 hours after $75 \mathrm{~g}$ oral glucose load.

insulin levels, and reduced total cholesterol and LDL-c, supporting the notion that micronized progesterone has a neutral effect on intermediate surrogate variables of cardiovascular risk [18]. Dansuk et al. [19] evaluated the effects of five combinations of HT in postmenopausal women, including $\mathrm{E} 2$ alone and E2 associated with medroxyprogesterone (E2+MPA), noretisterone (E2+NETA), dydrogesterone $(\mathrm{E} 2+\mathrm{DG})$ and micronized progesterone $(\mathrm{E} 2+\mathrm{P})$. $\mathrm{E} 2+\mathrm{NETA}$ and E2+DG were found to improve insulin sensitivity after 3 months of treatment, whereas E2+P or E2 alone did not show such any effect in postmenopausal women.

It is well established that oral E2 therapy in conventional doses induces an increase in hsCRP, while transdermal E2 has either no effect on or even reduces hsCRP levels in postmenopausal women [20]. Studies examining the effect of progestins on markers of inflammation have produced varying results [18]. In the present study there was no worsening of hsCRP during HT with or without progesterone.

A limitation of this study is the short duration of treatment (6 months or less), since in clinical practice patients are usually treated for one year or more. Nevertheless, previous studies have reported significant changes in lipids and markers of endothelial function [21] after 4 to 12 weeks of HT. In addition, evidence suggests that there is a "critical period" in the first months of HT, related to greater inflammatory activation and higher thromboembolic risk events. Further studies of longer duration will be helpful to confirm our findings.

\section{Conclusions}

Data from the present study suggest that the addition of micronized progesterone to non-oral E2 did not induce harmful effects on variables related to cardiovascular risk in a population of healthy, early postmenopausal women. Micronized progesterone did not interfere with the effects of non-oral E2, and did not abrogate the relief of symptoms. Finally, combined micronized progesterone and non-oral E2 treatment had neutral impact on blood pressure, body composition, lipid profile and markers of endothelial function.

\section{Methods}

\section{Study protocol}

This study is nested within a crossover randomized trial assessing the comparative effects of low-dose oral HT and non-oral HT on cardiovascular risk factors and markers of endothelial function in early postmenopausal women. Preliminary results of this trial (which focused on the comparison between non-oral estradiol-micronized progesterone or low-dose oral estradiol-drospirenone therapy on metabolic variables and markers of endothelial function in early postmenopause), including the first 40 women enrolled, have been published [22].

In the present analysis, 42 women received $3 \mathrm{mg} /$ day $17 \beta$ estradiol by intranasal route (Aerodiol ${ }^{\circledR}$, Servier, RJ, Brazil) for two months, and 53 received $1.5 \mathrm{mg} /$ day $17 \beta$ estradiol gel by percutaneous route $\left(\right.$ Oestrogel ${ }^{\circledR}$, Farmoquímica, SP, Brazil) for three months. Additionally, both groups received $200 \mathrm{mg} /$ day micronized progesterone (Utrogestan ${ }^{\circledR}$, Farmoquímica, SP, Brazil) together with estrogen treatment by vaginal route 14 days/month during the studied cycles (during 2 or three months, respectively). The following were compared: effects of type of non-oral estradiol (intranasal or percutaneous gel) before, during the estradiol only portion of the study (E2) and during the estradiol plus progesterone portion $(\mathrm{E} 2+\mathrm{P})$. The effects of $\mathrm{E} 2$ vs. $\mathrm{E} 2+\mathrm{P}$ for the overall group, regardless of route (intranasal or percutaneous), were also analyzed.

The 95 women enrolled for this trial fulfilled the following inclusion criteria: 1) last menstrual period between 6 months and 3 years before the beginning of the study plus follicle-stimulating hormone (FSH) levels higher than $35 \mathrm{IU} / \mathrm{L} ; 2$ ) age between 42 and 58 years; 3) no use of any medication known to interfere with hormonal, glucose or lipoprotein levels in the past 3 months; 4) no use of steroidal or non-steroidal anti-inflammatory drugs in the last 15 days. Patients presenting diabetes, previous hysterectomy, endometrial thickness higher than $0.5 \mathrm{~cm}$, history of cancer, thromboembolism or established CVD were excluded.

Nine patients dropped out in the first two months of follow-up (Figure 1). Therefore, 86 patients completed the study. Clinical evaluation was performed before the treatment was begun and monthly during the trial. Anthropometric measurements included body weight, height, waist circumference (measured at the midpoint 
between the lower rib margin and the iliac crest), hip circumference (measured at the level of the greater trochanter), waist-to-hip ratio (WHR), and BMI, current measured weight in $\mathrm{kg}$ divided by height in $\mathrm{m}^{2}$ ). The Kupperman score was assessed before and during treatment. Blood pressure was measured twice, at a 1min interval in seated patients, using a digital sphygmomanometer (Omron HEM 742, Rio de Janeiro, Brazil) with appropriate cuff for the arm diameter.

The study protocol was approved by the Ethics Committee at the Hospital de Clínicas de Porto Alegre, and written informed consent was obtained from every subject (IRB 0000921/05-053). The study was registered at clinicaltrials.gov (NCT01432028).

\section{Laboratory assessment}

Blood samples were collected before treatment, during the estradiol-only portion (E2) (days 12 to 14 of the second treatment month), and at the end of treatment (days 24 to 28 of the last month of estradiol plus micronized progesterone administration) (E2+P). All samples were obtained between 08:00 and 10:00 a.m. After a 12-hour overnight fast, blood samples were drawn from an antecubital vein for determination of FSH, estradiol (E2), lipid profile (total cholesterol, HDL-c and triglycerides) plasma glucose (oral glucose tolerance test), and insulin. Blood samples were also drawn for us-CRP.

Total cholesterol, HDL-c, triglycerides, and glucose were determined by colorimetric-enzymatic methods using the Bayer 1650 Advia System (Mannheim, Germany). LDL-c was estimated indirectly using the formula LDL $=$ total cholesterol - HDL-c - triglycerides $/ 5$.

Serum FSH was measured by electrochemiluminescence immunoassay (ECLIA), with intra and interassay coefficients of variation (CV) of $1.8 \%$ and $3.3 \%$ for $\mathrm{FSH}$. The sensitivity of the assay was $0.05 \mathrm{IU} / \mathrm{L}$ for FSH. Estradiol was measured by ECLIA (Roche Diagnostics, Mannheim, Germany), with an assay sensitivity of 5.0 $\mathrm{pg} / \mathrm{mL}$ and intra and interassay CV of 5.7 and $6.4 \%$. Serum insulin levels were measured using ECLIA (Roche Diagnostics, Mannheim, Germany), with sensitivity of $0.200 \mu \mathrm{IU} / \mathrm{mL}$ and intra and interassay $\mathrm{CV}$ of 2.0 and $4.3 \%$, respectively. Ultra-sensitive CRP was assayed using stored specimens, with a validated high-sensitivity nephelometric method (Dade Behring Marburg, Marburg, Germany). Sensitivity was $0.17 \mathrm{mg} / \mathrm{L}$ and intra and interassay $\mathrm{CV}$ were 4.4 and $5.7 \%$, respectively. For

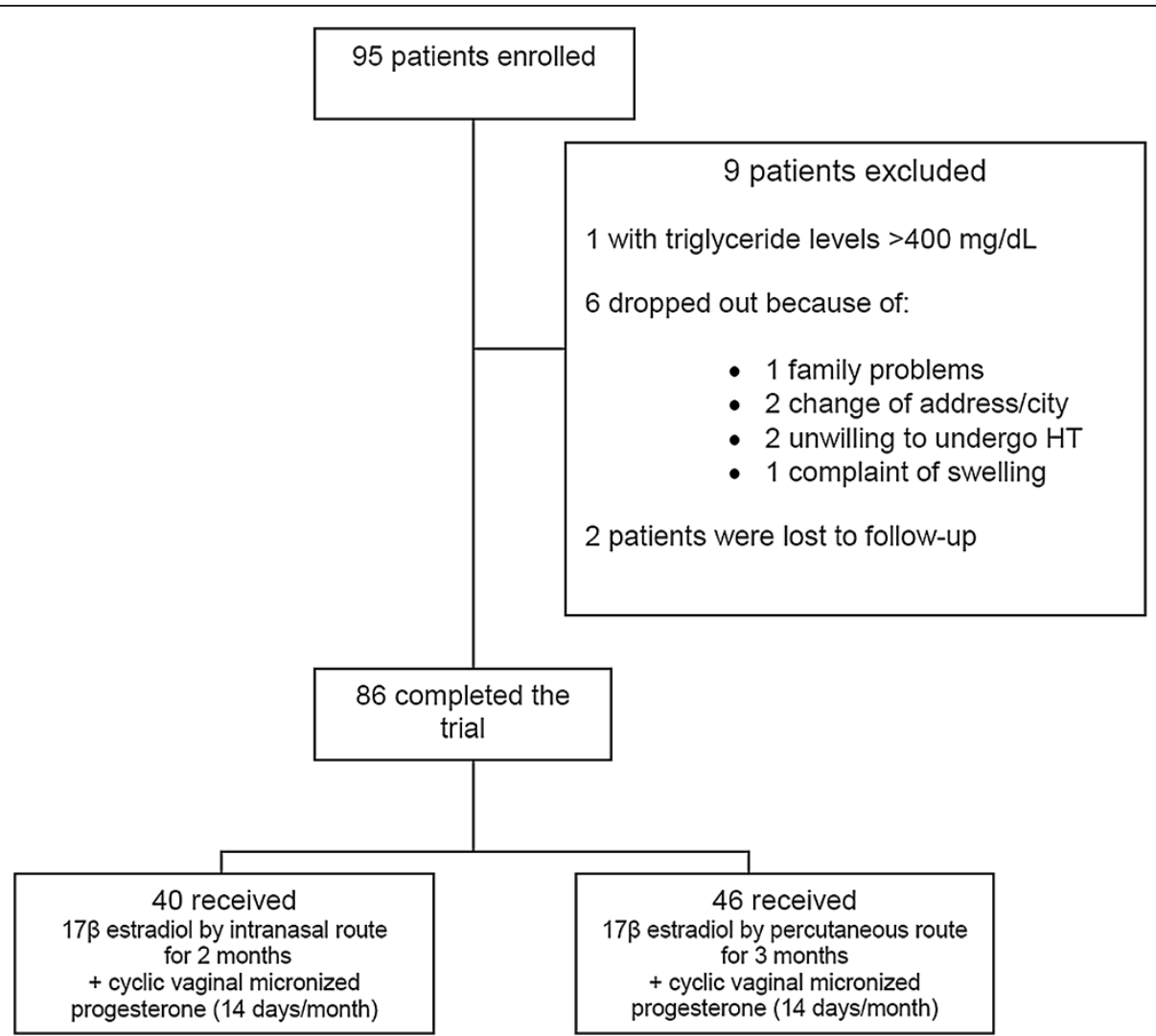

Figure 1 Representation of the design. Flowchart showing the total number of patients enrolled, number of dropouts, and group description. 
data analysis, individual results below the limit of sensitivity were considered as equal to $0.17 \mathrm{mg} / \mathrm{L}$.

\section{Statistical analysis}

Results are expressed as means \pm standard deviation (SD) or median and interquartile range. Log10 transformation was used to normalize the distribution of non-Gaussian variables. Two-way analysis of variance (ANOVA) with repeated measures was carried out for comparing basal conditions, E2 and $\mathrm{E} 2+\mathrm{P}$. Bonferroni adjustment was used for multiple comparisons. Friedman test was used for the analysis of Kupperman score, followed by the sign test. All analyses were performed using the Statistical Package for the Social Sciences (SPSS, Chicago, IL, USA) and Stata (StataCorp LP, Texas, USA). Data were considered to be significant at $\mathrm{P}<0.05$.

\begin{abstract}
Abbreviations
ANOVA: Analysis of variance; BMI: Body mass index; CRP: C-reactive protein; CV: Coefficients of variation; CVD: Cardiovascular risk; DBP: Diastolic blood pressure; DG: Dydrogesterone; E2: Estradiol; ECLIA: Electrochemiluminescence immunoassay; FSH: Follicle-stimulating hormone; HDL-c: High-density lipoprotein cholesterol; hsCRP: High-sensitivity C-reactive protein test; HT: Hormone therapy; LDL-c: Low-density lipoprotein cholesterol; MPA: Medroxyprogesterone; NETA: Noretisterone; P: Progesterone; SBP: Systolic blood pressure; SD: Standard deviation; SPSS: Statistical Package for the Social Sciences; usCRP: Ultra-sensitive C-reactive protein; WC: Waist circumference; WHR: Waist-to-hip ratio.
\end{abstract}

\section{Competing interests}

The authors declare that they have no competing interests.

\section{Authors' contributions}

GC and PMS contributed to acquisition of data, analysis and interpretation of data and manuscript review. PMS conceived and designed the study. Both authors contributed to the analysis and interpretation of data, drafting manuscript and final review, and both approved the final version of the manuscript.

\section{Acknowledgements}

This work was supported by grants from Conselho Nacional de Desenvolvimento Científico e Tecnológico (CNPq INCT 573747/2008-3) and Fundo de Apoio à Pesquisa do Hospital de Clínicas de Porto Alegre (FIPEHCPA 352/2009), Brazil.

\section{Author details}

${ }^{1}$ Gynecological Endocrinology Unit, Division of Endocrinology, Hospital de Clínicas de Porto Alegre (HCPA), Rua Ramiro Barcelos, 2350, 90035-003 Porto Alegre, Brazil. 'National Institute of Hormones and Women's Health, CNPq, Rua Ramiro Barcelos, 2350, 90035-003 Porto Alegre, Brazil. ${ }^{3}$ Laboratory of Molecular Endocrinology, Department of Physiology, Universidade Federal do Rio Grande do Sul (UFRGS), Rua Ramiro Barcelos, 2350, 90035-003 Porto Alegre, Brazil.

\section{Received: 7 April 2012 Accepted: 2 October 2012}

Published: 9 October 2012

\section{References}

1. Sare GM, Gray LJ, Bath PM: Association between hormone replacement therapy and subsequent arterial and venous vascular events: a meta-analysis. Eur Heart J 2008, 29:2031-2041.

2. Sherwin BB, Grigorova M: Differential effects of estrogen and micronized progesterone or medroxyprogesterone acetate on cognition in postmenopausal women. Fertil Steril 2011, 96:399-403.
3. Campagnoli C, Ambroggio S, Lotano MR, Peris C: Progestogen use in women approaching the menopause and breast cancer risk. Maturitas 2009, 62:338-342.

4. Nath A, Sitruk-Ware R: Different cardiovascular effects of progestins according to structure and activity. Climacteric 2009, 12(Suppl 1):96-101.

5. Archer DF: Progestogens: effects on clinical and biochemical parameters in postmenopausal women. Menopause 2005, 12:484-487.

6. Espeland MA, Hogan PE, Fineberg SE, Howard G, Schrott $H$, Waclawiw MA, Bush TL: Effect of postmenopausal hormone therapy on glucose and insulin concentrations. PEPI Investigators. Postmenopausal Estrogen/Progestin Interventions. Diabetes Care 1998, 21:1589-1595.

7. Reuben DB, Palla SL, Hu P, Reboussin BA, Crandall C, Herrington DM, BarrettConnor $\mathrm{E}$, Greendale GA: Progestins affect mechanism of estrogen-induced C-reactive protein stimulation. Am J Med 2006, 119(167):e161-e168.

8. Dubey RK, Imthurn B, Barton M, Jackson EK: Vascular consequences of menopause and hormone therapy: importance of timing of treatment and type of estrogen. Cardiovasc Res 2005, 66:295-306.

9. Canonico M, Plu-Bureau G, Scarabin PY: Progestogens and venous thromboembolism among postmenopausal women using hormone therapy. Maturitas 2011, 70:354-360.

10. Spritzer PM, Vitola D, Vilodre LC, Wender MC, Reis FM, Ruschel S, Castro I: One year follow-up of hormone replacement therapy with percutaneous estradiol and low-dose vaginal natural progesterone in women with mild to moderate hypertension. Exp Clin Endocrinol Diabetes 2003, 111:267-273.

11. Bukowska H, Stanosz S, Zochowska E, Millo B, Sieja K, Chelstowski K, Naruszewicz M: Does the type of hormone replacement therapy affect lipoprotein (a), homocysteine, and C-reactive protein levels in postmenopausal women? Metabolism 2005, 54:72-78.

12. Rossouw JE, Anderson GL, Prentice RL, LaCroix AZ, Kooperberg C, Stefanick ML, Jackson RD, Beresford SA, Howard BV, Johnson KC, et al: Risks and benefits of estrogen plus progestin in healthy postmenopausal women: principal results From the Women's Health Initiative randomized controlled trial. JAMA 2002, 288:321-333.

13. Naftolin F, Taylor HS, Karas R, Brinton E, Newman I, Clarkson TB, Mendelsohn M, Lobo RA, Judelson DR, Nachtigall LE, et al: The Women's Health Initiative could not have detected cardioprotective effects of starting hormone therapy during the menopausal transition. Fertil Steril 2004, 81:1498-1501.

14. Shufelt $C L$, Johnson $B D$, Berga $S L$, Braunstein $G D$, Reis $S E$, Bittner $V$, Yang Y, Pepine CJ, Sharaf BL, Sopko G, et al: Timing of hormone therapy, type of menopause, and coronary disease in women: data from the National Heart, Lung, and Blood Institutesponsored Women's Ischemia Syndrome Evaluation. Menopause 2011, 18:943-950.

15. Sowers MR, Randolph J Jr, Jannausch M, Lasley B, Jackson E, McConnell D: Levels of sex steroid and cardiovascular disease measures in premenopausal and hormone-treated women at midlife: implications for the "timing hypothesis". Arch Intern Med 2008, 168:2146-2153.

16. Seely EW, Walsh BW, Gerhard MD, Williams GH: Estradiol with or without progesterone and ambulatory blood pressure in postmenopausal women. Hypertension 1999, 33:1190-1194.

17. Bea JW, Zhao Q, Cauley JA, LaCroix AZ, Bassford T, Lewis CE, Jackson RD, Tylavsky FA, Chen Z: Effect of hormone therapy on lean body mass, falls, and fractures: 6-year results from the Women's Health Initiative hormone trials. Menopause 2011, 18:44-52.

18. Kwok S, Selby PL, McElduff P, Laing I, Mackness B, Mackness MI, Prais $H$, Morgan J, Yates AP, Durrington PN, Sci FM: Progestogens of varying androgenicity and cardiovascular risk factors in postmenopausal women receiving oestrogen replacement therapy. Clin Endocrinol (Oxf) 2004, 61:760-767.

19. Dansuk R, Unal O, Karsidag YK, Turan C: Evaluation of the effects of various gestagens on insulin sensitivity, using homeostatic model assessment, in postmenopausal women on hormone replacement therapy. Gynecol Endocrinol 2005, 20:1-5.

20. Menon DV, Vongpatanasin W: Effects of transdermal estrogen replacement therapy on cardiovascular risk factors. Treat Endocrinol 2006, 5:37-51. 
21. Shifren $J$, Rifai N, Desindes S, Mcllwain M, Doros G, Mazer NA: A comparison of the short-term effects of oral conjugated equine estrogens versus transdermal estradiol on C-reactive protein, other serum markers of inflammation, and other hepatic proteins in naturally menopausal women. J Clin Endocrinol Metab 2008, 93:1702-1710.

22. Casanova G, Radavelli S, Lhullier F, Spritzer PM: Effects of nonoral estradiolmicronized progesterone or low-dose oral estradiol-drospirenone therapy on metabolic variables and markers of endothelial function in early postmenopause. Fertil Steril 2009, 92:605-612.

doi:10.1186/1476-511X-11-133

Cite this article as: Casanova and Spritzer: Effects of micronized

progesterone added to non-oral estradiol on lipids and cardiovascular

risk factors in early postmenopause: a clinical trial. Lipids in Health and

Disease 2012 11:133.

\section{Submit your next manuscript to BioMed Central and take full advantage of:}

- Convenient online submission

- Thorough peer review

- No space constraints or color figure charges

- Immediate publication on acceptance

- Inclusion in PubMed, CAS, Scopus and Google Scholar

- Research which is freely available for redistribution 